\title{
fMRI of Cocaine Self-Administration in Macaques Reveals Functional Inhibition of Basal Ganglia
}

\author{
Joseph B Mandeville*,1,2, Ji-Kyung Choi ${ }^{1,2,5}$, Bechir Jarraya ${ }^{1,2,3,5}$, Bruce R Rosen ${ }^{1,2}$, Bruce G Jenkins ${ }^{1,2}$ and \\ Wim Vanduffel ${ }^{1,2,4}$ \\ 'MGHIMIT/HMS Athinoula A Martinos Center for Biomedical Imaging Massachusetts General Hospital, Boston, MA, USA; ${ }^{2}$ Department of \\ Radiology, Massachusetts General Hospital, Boston, MA, USA; ${ }^{3}$ Inserm Avenir Lab, Neurospin-CEA Saclay Center, Gif-sur-Yvette, France; \\ ${ }^{4}$ Laboratorium voor Neuro- en Psychofysiologie, Katholieke Universiteit Leuven, Leuven, Belgium
}

\begin{abstract}
Disparities in cocaine-induced neurochemical and metabolic responses between human beings and rodents motivate the use of nonhuman primates (NHP) to model consequences of repeated cocaine exposure in human subjects. To characterize the functional response to cocaine infusion in NHP brain, we employed contrast-enhanced $\mathrm{fMRI}$ during both non-contingent injection of drug and selfadministration of cocaine in the magnet. Cocaine robustly decreased cerebral blood volume (CBV) throughout basal ganglia and motorl pre-motor cortex and produced subtle functional inhibition of prefrontal cortex. No brain regions exhibited significant elevation of CBV in response to cocaine challenge. Theses effects in NHP brain are opposite in sign to the cocaine-induced fMRI response in rats, but consistent with previous measurements in NHP based on glucose metabolism. Because the striatal ratio of D2 to DI receptors is larger in human beings and NHP than rats, we hypothesize that the inhibitory effects of D2 receptor binding dominate the functional response in primates, whereas excitatory DI receptor stimulation predominates in the rat. If the NHP accurately models the human response to cocaine, downregulation of D2 receptors in human cocaine-abusing populations can be expected to blunt cocaine-induced functional responses, contributing to the weak and variable $\mathrm{fMRI}$ responses reported in human basal ganglia following cocaine infusion.

Neuropsychopharmacology (20 I I) 36, I I87-I 198; doi: I0.1038/npp.20 I I.I; published online 9 February 20 I I
\end{abstract}

Keywords: cocaine; self-administration; $\mathrm{MRI}$; CBV; NHP; monkey

\section{INTRODUCTION}

Neuroimaging studies of cocaine dependence and addiction in human populations face a series of obstacles. Ethical imperatives preclude controlled longitudinal studies of drug exposure, and cross-sectional studies are confounded by poly-drug abuse and variable exposure histories (Gatley et al, 2005). These issues impede an understanding of how biochemical stimulation of the brain evolves into drug dependence and addiction.

Animal systems, and particularly rodents, have been employed to model how repeated exposure to drug produces behavioral reinforcement and neurochemical adaptations, but disparate results between primates and rodents have been reported in response to acute or chronic cocaine infusion. Neurochemically, chronic exposure to drug is associated with unchanged or even reduced levels of

*Correspondence: Dr JB Mandeville, Department of Radiology, Massachusetts General Hospital, Building 149, Room 230I, I3th Street, Charlestown, MA 02129, USA, Tel: + I 6177260327 , Fax: + I 617726 7422, E-mail: jbm@nmr.mgh.harvard.edu

${ }^{5}$ These authors contributed equally to this work.

Received 22 September 20 I0; revised 7 December 20 0; accepted 20 December 2010 extracellular dopamine following drug infusion in human beings (Volkow et al, 1997; Martinez et al, 2007) and non-human primates (NHP) (Bradberry and Rubino, 2006; Kirkland Henry et al, 2009), whereas repeated exposure to cocaine in rats leads to dopaminergic sensitization in response to acute injection of drug (Kalivas and Stewart, 1991). Positron emission tomography (PET) studies of raclopride displacement suggest that D2/D3 receptor binding is reduced as a consequence of chronic cocaine exposure in both human beings (Volkow et al, 1993) and NHP (Nader et al, 2006), whereas the rodent literature on D2/D3 receptor regulation in response to repeated cocaine exposure is discordant (Narendran and Martinez, 2008). In terms of the systems' biological response, acute cocaine infusion has been reported to reduce cerebral metabolism in human subjects (London et al, 1990) and NHP (Lyons et al, 1996), but elevate metabolism in rats (Porrino, 1993).

fMRI facilitates cross-species comparisons (Vanduffel et $a l, 2002)$ and enables a wide variety of experimental strategies that exploit the temporal domain. However, the reported blood oxygen level-dependent (BOLD) response patterns to cocaine infusion in human cocaine-abusing populations have been inconsistent across studies, leaving an unsettled picture as to the nature of the cocaine-induced 
functional response in human beings. Comparisons of pre- and post-infusion periods, or correlations between MRI signal and subject ratings of euphoria, have found signal increases in basal ganglia (Breiter et al, 1997), bilateral signal reduction in accumbens without significant effects on caudate or putamen (Kufahl et al, 2005), or lateralized BOLD reductions in accumbens and putamen, but an increase in caudate (Risinger et al, 2005; Kufahl et al, 2008). In prefrontal cortex, the pattern again is variable across studies, with more regions responding positively than negatively.

Conversely to human studies, fMRI reports of the cocaine-induced response in rats have been broadly concordant. Using techniques that are sensitive to cerebral blood volume (CBV), cerebral blood flow (CBF), high-field BOLD signal, or cellular uptake of manganese through calcium channels (Marota et al, 2000; Mandeville et al, 2004; Schmidt et al, 2006; Lu et al, 2007), cocaine infusion increases cerebral activity in basal ganglia and cortical areas in agreement with previous autoradiographic measurements based on metabolism (Porrino, 1993) and CBF (Stein and Fuller, 1993). Positive cocaine-induced functional responses are largely blocked by a D1 receptor antagonist (Marota et al, 2000), suggesting a dominant role of D1 receptor stimulation by cocaine infusion in the rat. Because agonist/antagonist experiments have shown that stimulation of D1 and D2 receptor families produce opposite effects on fMRI signal (Marota et al, 2000; Chen et al, 2005; Choi et al, 2006), interspecies variations in the basal ratio of D1 to D2 receptors, or other synaptic targets, could alter functional responses in rats with respect to primates.

Although the NHP provides the closest neuroanatomical and neurochemical model for human drug abuse studies (Weerts et al, 2007), imaging the effects of drug stimuli in awake monkeys is technically challenging. Previous NHP neuroimaging studies using PET (Howell et al, 2002, 2010) have reported cocaine-induced elevation of cortical CBF, in apparent disagreement with previous reports of the metabolic effects of cocaine in NHP (Lyons et al, 1996) and with our preliminary fMRI reports in this model (Mandeville et al, 2005; Jarraya et al, 2007).

In this study, we report the cocaine-induced functional response in awake NHP using the sensitive "increased relaxation for optimized neuroimaging" (IRON) technique that has proven to be so effective for fMRI in rodents (Mandeville et al, 1998; Chen et al, 2001) and in NHP studies using sensory stimuli (Vanduffel et al, 2001; Leite et al, 2002). To maintain doses within a behaviorally relevant range and to evaluate a model of chronic cocaine exposure, we employed a contingent model of cocaine delivery in which we replaced the traditional bar-pressing procedure for drug self-administration with visual saccades to drug-reinforced targets. The self-administration taskand cue-associated functional responses has been presented in preliminary form (Choi et al, 2009).

\section{MATERIALS AND METHODS}

\section{Animal Model}

Experiments procedures were approved by the Subcommittee on Research Animal Care at the Massachusetts General
Hospital and conform to the Public Health Service standards of humane care and use of laboratory animals. The basic methods for performing fMRI in awake, behaving rhesus monkeys (Macaca mulatta) have been described in previous publications (Vanduffel et al, 2001; Leite et al, 2002). In addition, central venous catheters were implanted in the internal jugular vein of the two monkeys (M1 and M2) used in these studies and connected to an access port attached to the dental cement surrounding the head post; this venous line enabled iron oxide injection and drug delivery. During these studies, monkeys weighed 5-6 kg and were 5 and 8 years of age.

\section{Behavioral Task}

A simple visual choice task was designed to infuse drug according to behavioral selection. For baseline visual fixation, two identical white circular cues with central fixation dots were presented in the horizontal plane at a separation of $7^{\circ}$. During periods of cocaine availability, as indicated by a yellow border surrounding the presentation screen, choices between a white and yellow cue indicated the opportunity for drug delivery after fixation on the drugreinforced (yellow) cue for $6 \mathrm{~s}$, a period that did not need to be contiguous in time. Upon satisfying the fixation criteria for the yellow cue, $0.015 \mathrm{mg} / \mathrm{kg}$ of cocaine in a $0.5 \mathrm{mg} / \mathrm{ml}$ solution was infused at a rate of $10 \mathrm{ml} / \mathrm{min}$ over a time of about $1.2 \mathrm{~s}$. Presentation of the next cocaine-reinforced cue occurred after a lockout time that was inversely proportional to the fixation percentage on the previous cue, but never less than $15 \mathrm{~s}$; using this method, the total dose of injected drug was proportional to selection for the yellow cue. Including the time required to saccade to the yellow cue, monkeys fixated on cocaine-reinforced cues about $70 \%$ of the time that the cues were present. This resulted in an average duration between drug infusions of about $30 \mathrm{~s}$ $((6+15) / 0.7=30)$.

Initial training sessions in both monkeys used long periods of cocaine availability and restriction to reinforce selections for cocaine by ensuring that plasma levels of drug were higher during periods of cocaine availability relative to cocaine restriction. Initial fMRI experiments in monkey M1 (26 fMRI runs in nine sessions) employed this basic paradigm by using a single 15 -min period of cocaine availability during each fMRI run (Figure 1a). For the purposes of temporally separating the direct effects of cocaine (slow pharmacodynamics) from responses to cues (fast sensorimotor and cognitive processing), a modified experimental design was used in monkey M2 (20 fMRI runs in seven sessions) and in a subsequent set of experiments in monkey M1 (24 fMRI runs in eight sessions). In this design, alternate 5-min periods of availability and restriction were used (Figure 1b). The minimum duration of drug availability ( $5 \mathrm{~min}$ ) was selected to allow time for the druginduced response to nearly reach a maximum value so that peak response values could be compared across infusion paradigms. Although the basic pattern of cocaine-induced functional response were similar between the two scanning periods in monkey M1, the second scanning period produced significantly smaller responses and was not included in assessments of cocaine's direct effects to reduce potential effects from neuroadaptation to drug. 

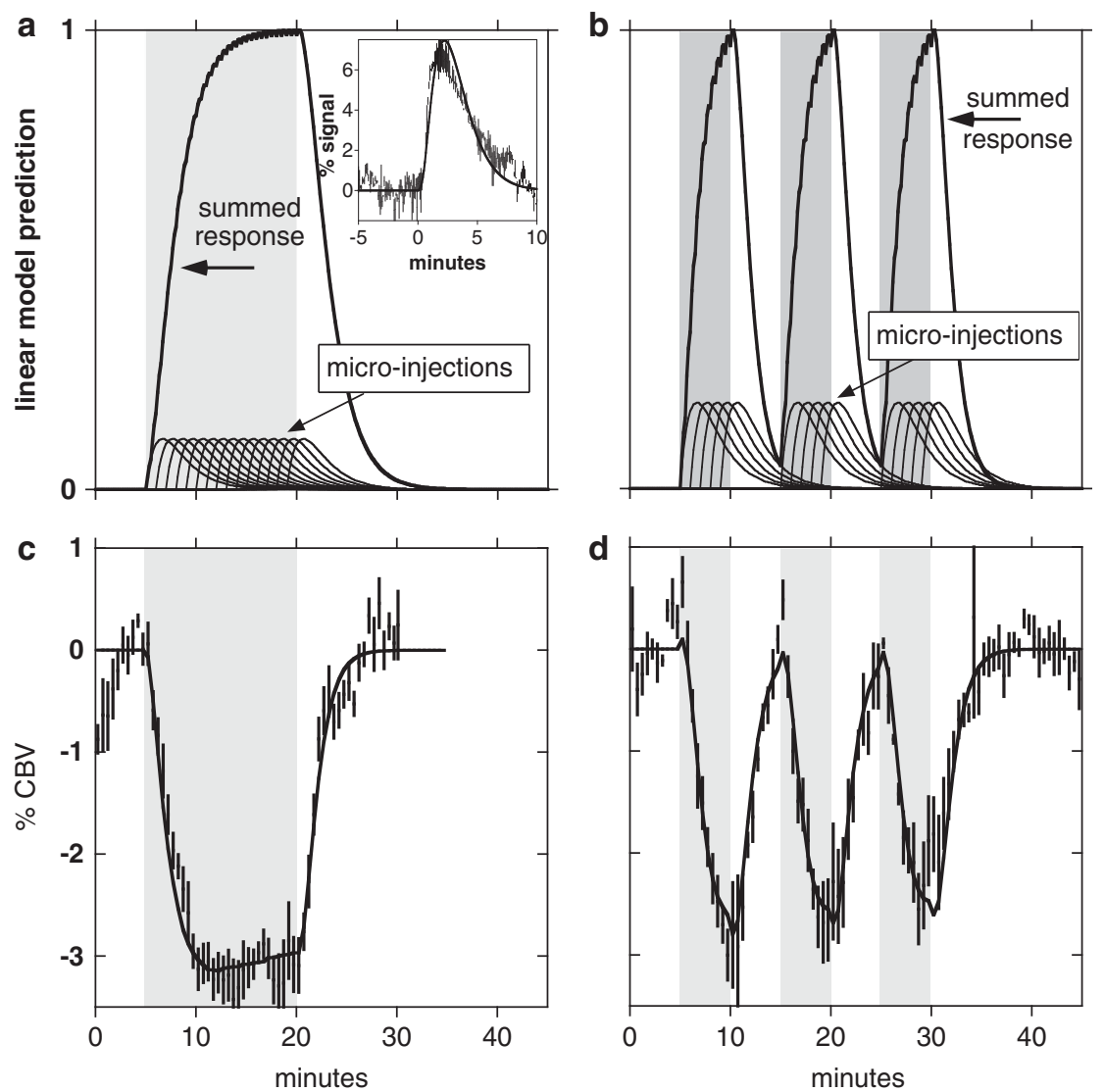

Figure I (a) Based on the measured non-contingent response to bolus infusion of $0.25 \mathrm{mg} / \mathrm{kg}$ cocaine (inset), the response to multiple microinjections can be predicted from a linear model during an extended period of cocaine availability (a) or periodic periods of drug availability and restriction (b). For simplicity, only half of the microinjections used to predict the total response are shown. Contingent infusion data (standard errors) from whole putamen are compared with predictions, which are the analysis regressors, based on the actual timing of infusions of $0.015 \mathrm{mg} / \mathrm{kg}$ cocaine in monkeys $\mathrm{MI}$ (c) and $\mathrm{M} 2$ (d).

\section{MRI Acquisition and Motion Correction}

All experiments employed a $3 \mathrm{~T}$ Trio scanner (Siemens Medical System, Erlangen, Germany). Data were acquired at an isotropic resolution of $1.2 \mathrm{~mm}$ across whole brain using two-dimensional echo-planar imaging, a repetition rate of $2 \mathrm{~s}$, and an echo time of $19 \mathrm{~ms}$. A four-channel coil array enabled twofold accelerated imaging by the GRAPPA method (Griswold et al, 2002) in a high-powered gradient insert ('AC88', Siemens Medical System, Erlangen, Germany); these methods reduced the sensitivity of images to motion in units of millimeters per hertz by a factor of 3.5 relative to non-accelerated imaging in a standard Trio system. Following image localization and before fMRI, monocrystalline iron oxide nanocompound was injected at an iron dose of $10-12 \mathrm{mg} / \mathrm{kg}$ to sensitize signal to changes in CBV (Leite et al, 2002).

For monkey fMRI using head fixation, standard rigidbody techniques that address real motion are inappropriate solutions to apparent brain motion that results from field perturbations induced by body motion. Apparent brain motion in our model consisted of a shift in the phaseencoding direction (left-right) that increased nonlinearly in the posterior and ventral directions near the monkey body. Consequently, we employed a custom motion-correction algorithm consisting of a shift parameter to account for global changes in the magnetic field, as previously described by others (Pfeuffer et al, 2007), plus a deformation term described as a position-dependent shift in the phaseencoding direction.

\section{Spatial Coordinates and Regions of Interest}

Session-averaged functional volumes were registered to a stereotaxic space for rhesus monkey brain (Saleem and Logothetis, 2006) using the population-averaged T1weighted rhesus monkey brain (McLaren et al, 2009) as the registration target. Automated alignment employed a 12-parameter affine registration, followed by adjustment of three-dimensional nonlinear distortion fields using publicly available software by the first author (www.nitrc.org/ projects/jip).

Regions of interest employed were defined from the Saleem-Logothetis atlas in conjunction with the anatomical contrast provided by the macaque MRI templates, and the definitions of cortical regions were informed by the probabilistic surface atlases of Lewis and Van Essen (2000) and Ferry et al (2000) as visualized by CARET software (Van Essen et al, 2001). The anterior-posterior division of putamen was marked at $19 \mathrm{~mm}$ anterior to ear bars; this division was selected (1) to reflect rostro-caudal gradients of D1 and D2 receptors (Piggott et al, 1999), and (2) because apparent longitudinal changes in the cocaine-induced 
response in monkey M1 (Figure 6) were most pronounced in the anterior portion of putamen. The region defined as OFC primarily included Brodmann areas (BA) 11 and 12; this region was restricted to slices $38-44 \mathrm{~mm}$ anterior to ear bars on the volumetric data set. DLPFC included areas 45 and 46, but excluded area 9; based on the resolution of this study, it also included small contributions from areas 44 and $8 \mathrm{~A}$. Anterior cingulate cortex (ACC) was restricted to slices $34-40 \mathrm{~mm}$ anterior of ear bars. The region defined as posterior cingulate cortex (PCC) was centered at $12 \mathrm{~mm}$ anterior to ear bars and extended $8 \mathrm{~mm}$ in both anterior and posterior directions, so that it included the posterior aspect of ACC. The area defined as 'motor' included contributions from BAs 1-4 on slices 14 and $15 \mathrm{~mm}$ anterior to ear bars. Amygdala was restricted to slices $0-3 \mathrm{~mm}$ dorsal to ear bars.

\section{Statistical Analysis}

Statistical analyses for each fMRI run employed the standard general linear model (GLM) after spatial smoothing using an isotropic $2 \mathrm{~mm}$ Gaussian kernel. Regressors unrelated to the effects of cocaine included a third-order polynomial to account for signal drift, motion-correction parameters as described previously, mean values and standard deviations of eye traces, total fixation percentage, and the cues presented for the contingent task. All regressors except motion parameters were convolved with our previously reported hemodynamic response function for IRON fMRI (Leite et al, 2002). Time-course data shown in Figure 1 have been corrected to remove baseline variations and the effects of non-cocaine regressors, as fit within the GLM.

Regressors for the direct effects of cocaine were based on the measured response to non-contingent cocaine injection together with the timing of cocaine infusions defined by the selection of reinforced cues. Figure la (inset) shows the response of whole putamen to a non-contingent infusion of $0.25 \mathrm{mg} / \mathrm{kg}$ cocaine that was administered over $30 \mathrm{~s}$; note that a positive signal response corresponds to a reduction in $\mathrm{CBV}$. The response reaches a peak value within $2.5 \mathrm{~min}$. To model the measured cocaine response for this extended duration of cocaine infusion and derive an appropriate estimation for a very short bolus, we used a gamma-variate function that peaked at $100 \mathrm{~s}$ as an impulse response model, and the curve in the figure (inset) resulted from convolution of this impulse response function with the 30-s infusion duration. In this study of contingent cocaine administration, microinjections of cocaine were delivered in less than $2 \mathrm{~s}$, so we used the gamma-variate function without temporal convolution to describe the impulse response to each infusion based on the actual timing recorded by the behavioral computer. The total response to cocaine was predicted by summating the individual responses, as depicted in Figure 1a and $b$.

To account for cross-session and cross-subject variance for the production of the statistical maps, we used a second-level GLM (Worsley et al, 2002) across repeated measurements using $46 \mathrm{fMRI}$ runs in 16 sessions (seven sessions for monkey $\mathrm{M} 1$, and nine sessions for monkey M2), as shown in Figure 2c. Functional maps show the percentage change in CBV for all voxels that passed a statistical threshold of $p<0.05$ after correction for multiple comparisons across 30000 resolution elements in the brain (Worsley et al, 1996).

\section{RESULTS}

At the beginning of fMRI experiments, lifetime cumulative cocaine doses were 27 and $75 \mathrm{mg} / \mathrm{kg}$ in monkeys M1 and $\mathrm{M} 2$, respectively. By the end of these experiments, cumulative doses were 75 and $102 \mathrm{mg} / \mathrm{kg}$. During fMRI and training sessions, the timing and cumulative doses of cocaine were dependent on behavior, but animals typically received about two infusions per minute. This infusion rate approximately equals the rate of cocaine infusions by self-administration using single bar presses with this unit dose of drug (Flory and Woods, 2003). During the $15 \mathrm{~min}$ of cocaine availability allowed within each fMRI run, cumulative cocaine doses per fMRI run were $0.51 \pm 0.10 \mathrm{mg} / \mathrm{kg}$ $($ mean $\pm \mathrm{SD})$ in monkey $\mathrm{M} 1$ and $0.42 \pm 0.07 \mathrm{mg} / \mathrm{kg}$ in monkey M2.

Figure 1 shows the temporal responses of whole putamen to cocaine infusion in the two monkeys using a single 15-min block of cocaine availability in monkey M1 (Figure 1c) and repeated on-off blocks of drug availability in monkey M2 (Figure 1d). Data are presented in 30-s time bins to simplify presentation. Analysis regressors (solid lines) were derived from shifted summations of a parametric response curve that was determined from the measured response induced by a larger non-contingent dose of cocaine (Figure 1a and b). Clearly, the assumption of temporal linearity proved to be accurate for this dose regimen, as the shape of the analysis regressor provided an excellent fit to data in basal ganglia.

The response to repetitive cocaine stimulation using this small unit dose showed little indication of acute tolerance across fMRI runs within each session, as illustrated by Figure 2c. Because subtle effects of acute tolerance within runs can be lost in corrections for signal drift, we additionally analyzed data by employing three separate regressors to fit cocaine-induce responses during each of the three periods of drug availability for monkey M2. In this analysis, responses to the second and third infusion trains were reduced progressively relative to those from the first period by $11 \pm 10$ and $20 \pm 12 \%$, respectively, but these effects did not reach significance across sessions.

Contingent and non-contingent cocaine infusion produced similar spatial patterns of CBV reduction throughout basal ganglia and motor cortex (Figure $2 \mathrm{~b}$ and $\mathrm{d}$ ). Both maps show all positive and negative cocaine-induced $\mathrm{CBV}$ changes that reached statistical significance using a blue-green color range for negative changes in $\mathrm{CBV}$ and a red-yellow color range for positive changes. Note that the non-contingent map in Figure $2 \mathrm{~b}$ uses a fourfold larger range of $\mathrm{CBV}$ changes than used for the contingent data in this or other figures. Figure $2 c$ shows the response of $\mathrm{CBV}$ in putamen during all self-administration sessions; points and error bars were derived from the first-level GLM analysis and represent peak response magnitudes of the regressors that were fit to the data (see Figure $1 \mathrm{c}$ and $\mathrm{d}$ ). Responses were consistent between the two monkeys and across imaging sessions.

Figure 3 shows the cocaine-induced functional response using a mosaic format of 15 transverse slices across basal ganglia from +9 to $+20 \mathrm{~mm}$ in a standard stereotaxic coordinate system (Saleem and Logothetis, 2006). Data were registered to the multi-subject macaque brain template 

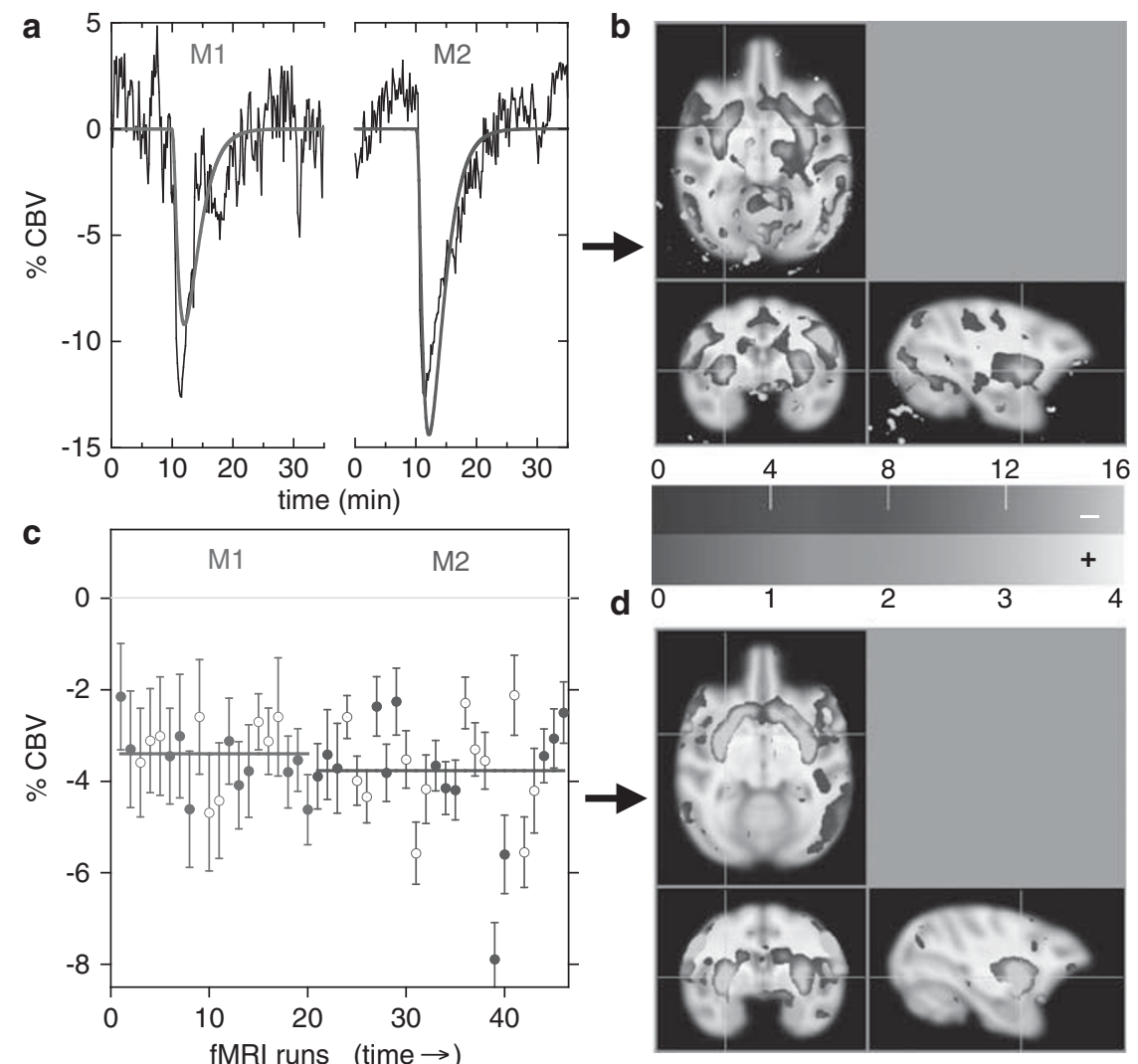

Figure 2 Non-contingent ( $\mathrm{a}, \mathrm{b})$ and contingent ( $\mathrm{c}, \mathrm{d})$ data. (a) The temporal response of whole putamen to bolus injection of $0.5 \mathrm{mg} / \mathrm{kg}$ cocaine in monkeys MI and M2. (b) Percentage changes in CBV generated from the non-contingent infusion data. (c) Repeated measurements from whole putamen using cocaine self-administration. Each point indicates a result from one $\mathrm{MMRI}$ run, and groups of adjacent filled or open circles correspond to multiple runs within a single fMRI session. Lines represent the average response magnitude for each monkey after accounting for error bars. (d) The spatial pattern during self-administration produced from a random-effects analysis across all fMRI runs; note the fourfold smaller scale relative to the non-contingent map. Colored voxels in both maps passed a statistical threshold of $p<0.05$ after a correction for multiple comparisons. See online version for color information.

(McLaren et al, 2009) that underlies the functional map in the figure, and outlines of putamen, caudate, and accumbens were defined using T1- and T2-based image contrast from the averaged MRI brain template in conjunction with coordinates from the stereotaxic atlas. Assuming a coupling between fMRI and metabolic responses, all regions of basal ganglia exhibit pronounced functional inhibition. In addition, decreases in CBV were clearly evident in motor and premotor cortex.

Responses to cocaine in prefrontal cortex were smaller and more variable across monkeys. Figure 4 depicts the subject-averaged cocaine-induced response in frontal cortex on a partially inflated cortical surface. Brodmann boundaries rely on the probabilistic atlases of Lewis and Van Essen (2000) together with Ferry et al (2000). Although bilateral cocaine-induced reductions of $\mathrm{CBV}$ were pronounced throughout premotor cortex (BA 6 in the figure) and motor cortex posterior to BA 6, orbital frontal cortex (BA 11, BA 12) and dorsolateral prefrontal cortex (BA 46, BA 45 inside sulcus) showed smaller and more lateralized reductions of $\mathrm{CBV}$.

Figure 5 quantifies regional changes in both monkeys. Using a conservative across-session analysis, cocaine infusion decreased CBV significantly throughout basal ganglia in each monkey, including the anterior and posterior putamen, caudate, and nucleus accumbens $(p<0.01$ after correction for multiple comparisons using Dunnett's method). When averaged across animals, all regions listed in the figure exhibited significant decreases in CBV, except for primary visual cortex, ACC and PCC, and amygdala. No regions responded differently between monkeys $(p>0.05)$. No cocaine-induced increases in CBV were observed in any regions that reached significance by conservative randomeffects statistical analysis within or across monkeys.

The spatiotemporal response to cocaine was specific to injection of drug. In two sessions in monkey M2, the pump was turned off during alternating periods of cocaine availability to compare responses with and without infusion of drug. In two sessions in monkey M1 and three sessions in monkey M2 that occurred after all cocaine-reinforcement studies, saline was substituted for cocaine. Pooling these data to create a control group for an analysis of regional effects across monkeys owing to infusion of drug, the same regions shown in Figure 5 reached significance, except for DLPFC.

\section{DISCUSSION}

As a monoamine transporter blocker, cocaine acts as an indirect agonist for dopamine, serotonin, and norepinephrine neurotransmitters (Ritz et al, 1990). As such, regional 


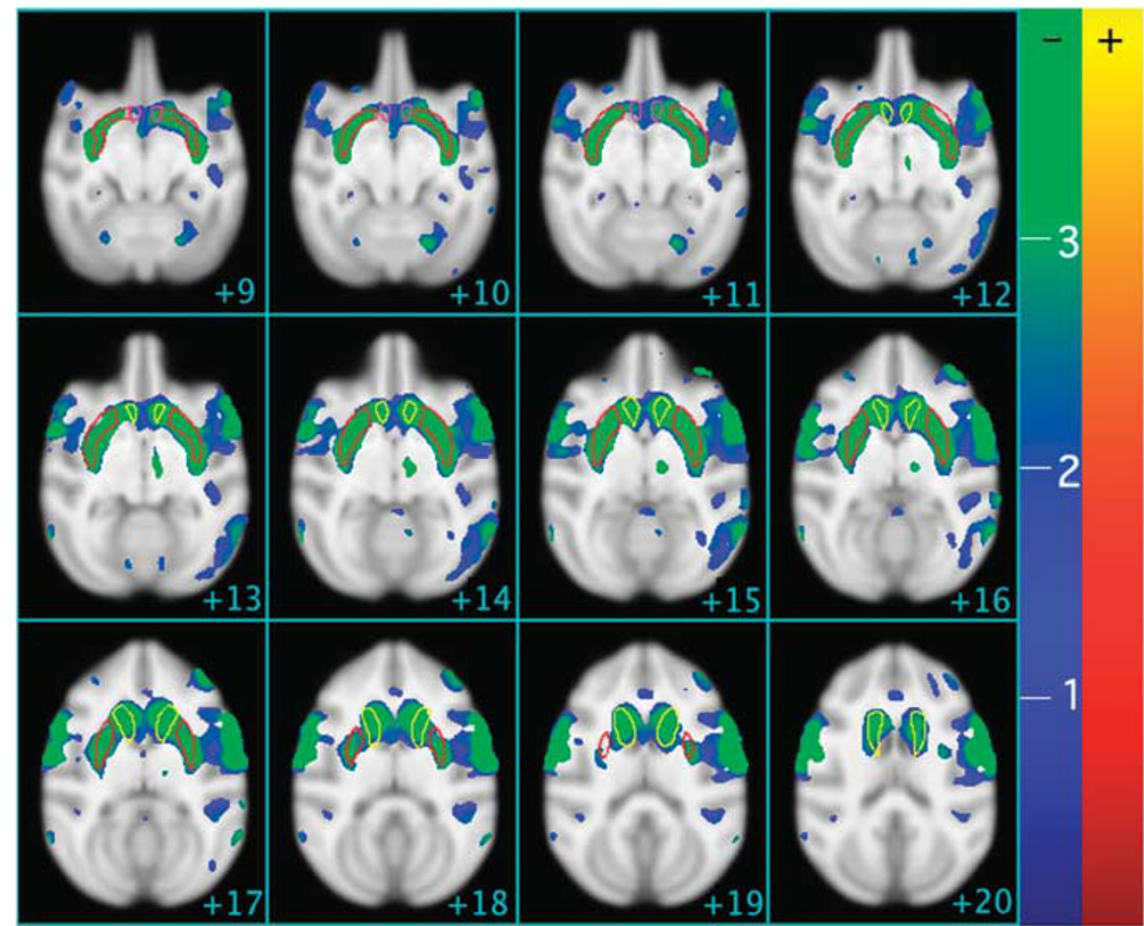

Figure 3 A spatial map of the peak magnitude of the cocaine-induced response averaged across animals, transposed onto a population-averaged rhesus brain (McLaren et al, 2009), and reported as a percentage change in CBV, with negative changes using the blue-green color scale and positive changes using the red-yellow scale. Slices cover basal ganglia from 9 to $20 \mathrm{~mm}$ anterior to ear bars in a stereotaxic coordinate space (Saleem and Logothetis, 2006). Highlighted regions include putamen (red lines), caudate (yellow), and nucleus accumbens (purple).

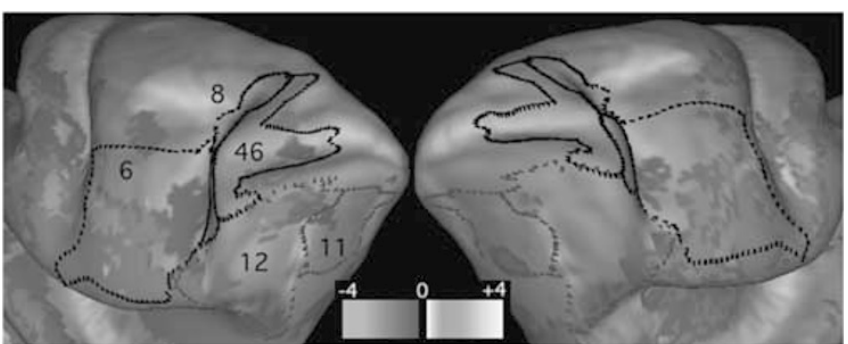

Figure 4 Functional activation in the frontal cortex measured as the percentage change in CBV (color scale) for regions that responded significantly by a random-effects analysis across $\mathrm{fMRI}$ sessions and monkeys. Activity is shown on right and left partially inflated hemispheres of the F99 cortical surface template (Van Essen et al, 200I). Numerals indicate Brodmann areas based on macaque probabilistic atlases: black borders from Lewis and Van Essen (2000); green borders from Ferry et al (2000). See online version for color information.

cocaine-induced changes in fMRI signal represent the summated effects of elevated extracellular levels of multiple neurotransmitters that can be excitatory or inhibitory at neural or vascular receptors to produce responses that are either local or distributed through neural circuitry. Despite this obvious complexity, as well as incomplete understandings of neurovascular coupling mechanisms, empirical data support the notion that cocaine-induced fMRI signal changes can be viewed as a metabolic surrogate. Autoradiographic measurements in the rat show that the regional coupling ratio between blood flow and glucose utilization is preserved during cocaine stimulation (Sharkey et al, 1991). Consistent with cocaine-induced effects on

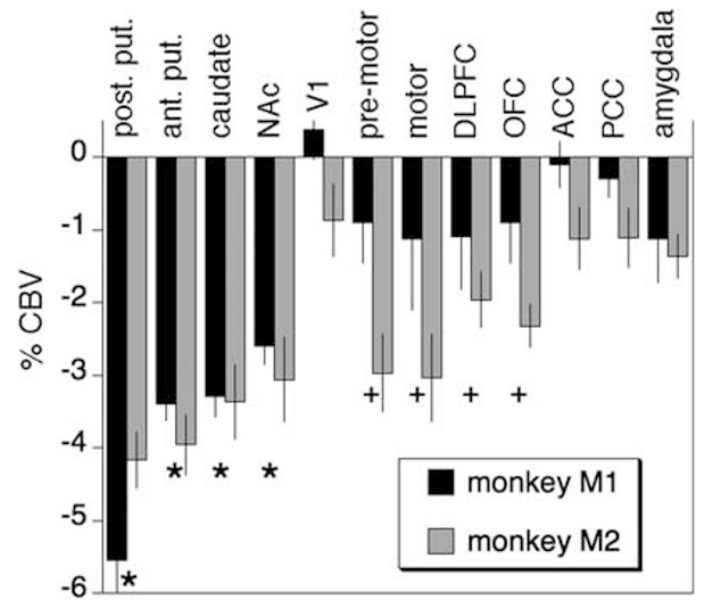

Figure 5 Functional changes in CBV (mean \pm standard error) associated with cocaine infusion. Asterisks indicate significance $(p<0.0 \mathrm{I})$ in each monkey across sessions after correction for multiple comparisons. Plus signs indicate significance averaged across animals.

glucose metabolism in rats and NHP (Lyons et al, 1996), the fMRI response to cocaine in the NHP is opposite in sign to the response observed in the rat.

Interpreting the systems-level functional response to a complex drug like cocaine requires consideration of the spatiotemporal profile of signal changes and the underlying metabolic contributions. We argue that the fMRI response to cocaine in the NHP strongly implicates dopaminergic mechanisms, and that known species-dependent differences 
in dopaminergic receptor concentrations probably underlie observed differences in functional responses to cocaine. The NHP provides a model for interpreting cocaine-induced fMRI signal changes in human beings and associating these changes with cocaine-induced neuroplasticity.

\section{Cocaine-Induced fMRI Response in NHP}

Although cocaine binds to multiple neurotransporters, the fMRI spatial response to cocaine in the NHP (Figure 3) most closely mimics the pattern of dopamine transporter density (McCann et al, 1998; Tsukada et al, 2001), dopamine D2 receptor density (Volkow et al, 1993; Nader et al, 2006), and cocaine binding (Fowler et al, 1989), all of which localize to basal ganglia in human beings and NHP as shown by PET. Conversely, the fMRI response does not match the reported spatial distribution of norepinephrine transporters, which are not found at detectable levels in cat or NHP caudate (Charnay et al, 1995; Seneca et al, 2006), or the spatial distribution of serotonin transporters, which are most dense in mid-brain, and more uniformly distributed throughout brain than the other monoamine transporters (Huang et al, 2002). These considerations suggest that the fMRI response in basal ganglia primarily arises from dense dopaminergic processes, which may be modulated by serotonin and norepinephrine.

In addition to functional inhibition of basal ganglia, cocaine-induced decreases in cortical CBV were most pronounced in motor regions, but also included some effects in prefrontal cortex. Because fMRI assesses brain function through flow-metabolism coupling, the signal reflects the biochemical effects of cocaine both at binding sites and in associated circuitry. Functional responses in both motor and prefrontal cortex are consistent with cortico-basal ganglia pathways, in which outputs from basal ganglia project back to motor and prefrontal cortex through segregated but parallel pathways through globus pallidum, mid-brain, and thalamic nuclei to cortex (Haber and Calzavara, 2009). Although rodent and primate basal ganglia differ anatomically and functionally, rodent data support the notion that much of the cortical response arises from striatal projections; unilateral 6-OHDA dopaminergic lesions along the nigrostriatal pathway in anesthetized rats ablate the fMRI response to dopaminergic stimuli in both ipsilesional striatum and cortex (Chen et al, 1999; Nguyen et al, 2000). Relative to cocaine-induced response patterns in rats, which exhibit widespread cortical activation using metabolic, cellular, or vascular markers of function (Sharkey et al, 1991; Marota et al, 2000; Lu et al, 2007), the functional response in NHP was more circumscribed within the mesolimbic system. Given the pronounced species differences in cortical anatomy and dopaminemediated connectivity between cortex and striatum/midbrain (Goldman-Rakic et al, 1999), it is difficult to isolate a single explanation for less expansive cocaine-induced cortical activity in the NHP. However, it has been suggested that the low density of D1 receptors in the middle input layers of NHP cortex may reflect less dopaminergic innervation of cortex via thalamic pathways (Richfield et al, 1989).

In the temporal domain, a bolus infusion of cocaine induced an fMRI response that reached a peak value in basal ganglia in less than $3 \mathrm{~min}$. This result is consistent with microdialysis of cocaine-induced extracellular dopamine, which reaches a peak response between 2 and 4 min in NHP basal ganglia (Bradberry, 2000). The response of fMRI signal also is consistent with the rapid removal of cocaine from arterial blood plasma by redistribution before the slower elimination phase; in both human beings (Evans et al, 1996) and rats (Booze et al, 1997), the redistribution half-life is faster than $1 \mathrm{~min}$, and arterial concentrations of cocaine drop fivefold during the first $5 \mathrm{~min}$. Because residual levels of cocaine in the plasma are eliminated slowly over tens of minutes, repeated boluses during a selfadministration task presumably produce progressive effects from accumulation, but small low-frequency responses are difficult to distinguish from other sources of signal drift.

A striking feature of these data are that the cocaineinduced fMRI response in rhesus monkeys is opposite in sign to the result seen in rats using BOLD or IRON fMRI (Marota et al, 2000; Mandeville et al, 2001) or blood flow (Stein and Fuller, 1993). This result agrees with a previous study based on invasive autoradiography (Lyons et al, 1996), which reported cocaine-induced reductions of glucose metabolism in a different NHP species (Macaca fascicularis), in contrast to results obtained in rats by the same group (Porrino, 1993) or others (Sharkey et al, 1991). The change in response from excitatory in the rat to inhibitory in the NHP, according to fMRI and metabolic indices, occurs despite the rough equivalence in the percentage elevation of extracellular dopamine in each species following injection of $0.5 \mathrm{mg} / \mathrm{kg}$ (Bradberry, 2000; Schwarz et al, 2004), the dose employed in Figure 2a. The opposite cocaine-induced responses in motor cortex between the two species have behavioral correlates: cocaine infusion increases gross locomotor activity in rodents (Kalivas and Stewart, 1991), but not in NHP (Bradberry, 2007). Because rats are such a mainstay of biomedical research, it is critical to understand the mechanisms underlying the profoundly different response to cocaine in research rat strains relative to primates, particularly in basal ganglia regions associated with behavioral reinforcement for the intake of drugs that elevate dopamine.

D1 antagonism and D2 agonism both decrease CBV by fMRI, whereas D1 agonism and D2 antagonism increase CBV (Marota et al, 2000; Chen et al, 2005; Choi et al, 2006), illustrating the opposite effects of stimulation of these receptor subtypes on fMRI signal in rats using an indirect dopaminergic agonist like cocaine. Data relating selective stimulation of dopaminergic receptor subtypes to flowmetabolic effects in NHP are sparse, but D2 and D3 agonists both decrease fMRI signal in basal ganglia in NHP (Black et al, 1997; Sanchez-Pernaute et al, 2007), consistent with rats. Therefore, species differences in the relative densities of D1 vs D2 receptor families could account for observed species differences in response to cocaine. Radioligand binding assays support this hypothesis; in rat striata, the reported ratio of $\mathrm{D} 1$ to $\mathrm{D} 2$ receptor densities is nearly 3 (Hyttel and Arnt, 1987; Weed et al, 1998), whereas the same ratio in rhesus or cynomolgus striata is slightly larger than unity (Madras et al, 1988; Weed et al, 1998). Postmortem studies in human subjects also show similar D1 and D2 striatal receptor densities (Hall et al, 1994; Piggott et al, 1999). Thus, the sign of cocaine-induced changes in flow 
and metabolism in basal ganglia may reflect the dominant effects of D2 stimulation in human beings and NHP and D1 stimulation in rats.

Although species differences in the basal D1/D2 receptor ratio might well explain the opposite cocaine-induced functional responses observed in the NHP relative to the rat, several points warrant further discussion. First, this difference apparently cannot be generalized as a primaterodent disparity, as autoradiography consistently has found cocaine-induced decreases in glucose utilization in mice (Rogers and Nahorski, 1973; Thanos et al, 2008), including one explicit comparison showing opposing results in mice and rats (Zocchi et al, 2001); no fMRI studies to date have evaluated the acute response to cocaine in mice. Wild-type mice appear to have similar levels of D1 and D2 receptor densities (Thompson et al, 2010), like primates and unlike the rat. Because pharmacological stimulation of D2 receptors has been shown to increase aggressive behavior in mice and cats (Puglisi-Allegra and Cabib, 1988; Sweidan et al, 1990; Nikulina and Kapralova, 1992), high D1/D2 ratios in rat research strains might be a consequence of selective breeding to decrease aggression, rather than a general trait of the rat species. To further complicate this issue, juvenile rats exhibit negative CBV changes in response to cocaine and little response to a D1 receptor agonist, whereas adult rats exhibit strong positive changes in CBV owing to infusion of cocaine or D1 agonist (Chen et al, 2010), further supporting the predominance of D1 stimulation in the cocaine response in adult rats.

The D1/D2 hypothesis does not simply explain why stimulation by amphetamine, but not cocaine, produces a positive fMRI response in NHP basal ganglia (Jenkins et al, 2004). This difference between cocaine and amphetamine emphasizes that a functional response to a pharmacological stimulus depends on the summation of all factors contributing to neural/vascular activity. In particular, amphetamine pre-synaptically stimulates dopamine release, which can be linked to elevated levels of intracellular calcium (Gnegy et al, 2004) and thereby to mechanisms that increase blood flow and metabolism (Jakovcevic and Harder, 2007). In addition, cocaine impacts non-dopaminergic neurotransmitter systems like serotonin. Selective receptor antagonism of cocaine-induced effects ultimately will be required to more fully elucidate the neurochemistry underlying fMRI signal changes to psychostimulants like cocaine and amphetamine.

\section{Comparisons with Neuroimaging of Cocaine in Human Beings and NHP}

Inconsistencies in the cocaine response patterns reported by BOLD fMRI in human beings probably reflect biological adaptations to chronic drug use, competing influences of biochemical stimulation and cognitive processing, and technical limitations of BOLD fMRI. If the NHP accurately models the human response to cocaine, then downregulation of D2 receptors in human cocaine abusers likely produces a blunted (less negative) fMRI response in basal ganglia relative to the drug-naïve condition. Cognition and cocaine stimulation can produce opposite influences on fMRI signal, which are not easily disentangled. A recent study showed that an expectation of drug delivery modulates the BOLD response pattern, primarily in frontal cortical regions (Kufahl et al, 2008). Finally, all human BOLD studies of cocaine infusion have employed the most common clinical field strength, 1.5 Tesla. At this magnet field, BOLD fMRI is about fivefold less sensitive than the IRON method (Mandeville et al, 1998; Vanduffel et al, 2001). Future human BOLD studies at high field should offer better insight into the cocaine-induced functional response in human subjects.

Only a very few studies have reported flow responses to cocaine in awake NHP. Two PET studies assessed the functional response to non-contingent cocaine delivery using radiolabeled water to measure $\mathrm{CBF}$ at a time point 5 min after infusion of cocaine (Howell et al, 2002, 2010). Those studies reported activation of dorsomedial cortical regions in coronal slices at the level of the caudate, regions where we did not detect significant signal changes. Because the PET acquisitions were normalized to global CBF, decreases in blood flow in one area (eg, basal ganglia) might be indistinguishable from increases in other areas. In addition, the most recent paper by that group explicitly ignored regional decreases in CBF (Howell et al, 2010).

\section{Does the Sign of the Cocaine-Induced fMRI Response Matter?}

If our hypothesis about the origin of the opposite cocaineinduced fMRI responses in the rat and NHP is correct, then measurements of flow and metabolism reflect a somewhat different balance of the same underlying processes in both species, and the fMRI signatures associated with the modulation of dopaminergic receptors will be different in the two species. For instance, downregulation of D2 receptors in the absence of other neuroadaptations should produce a smaller negative cocaine-induced fMRI response in the NHP, but a larger positive cocaine-induced response in the rat. Conversely, a reduced BOLD response in cocainetreated rats (Febo et al, 2005) cannot be explained by the downregulation of $\mathrm{D} 2$ receptors and/or upregulations of D1 receptors, but potentially could indicate higher D2 and/or lower D1 expression following chronic cocaine treatment.

Inconsistencies between the rodent and primate literature pose the question as to whether the relative balance of basal receptors influences neuronal plasticity owing to repeated cocaine exposure. Homeostasis is a concept that often is invoked to rationalize receptor regulation in response to chronic drug exposure (Volkow et al, 1990) or in model preparations following acute exposure to a receptor agonist (Dumartin et al, 1998). In terms of mitigating the metabolic consequences of repeated cocaine infusion, downregulation of D2 receptors and/or upregulation of D1 receptors would represent homeostatic reactions to repeated dopaminergic stimulation in the NHP. Longitudinal studies in NHP have shown a decrease in D2 receptor binding potential during chronic cocaine exposure (Moore et al, 1998a; Nader et al, 2006; Beveridge et al, 2009), and human studies find reduced D2 binding in cocaine abusers relative to control subjects (Volkow et al, 1993). The literature on D1 regulation in response to drug exposure in the NHP is somewhat more variable, with two studies finding increased D1 receptor densities following cocaine self-administration 
(Nader et al, 2002; Beveridge et al, 2009) and one study finding reduced D1 receptor levels (Moore et al, 1998b).

Although homeostasis is a useful general notion to argue that neuronal processes evolve to counter repeated stimulation, the actual mediators of plasticity are unknown. Do neurotransmitter systems evolve to attenuate the metabolic consequences of repeated stimulation, so that receptor adaptations to repeated drug exposure are different in rats and NHP? Under this hypothesis, rats subjected to repeated cocaine exposure should exhibit upregulation of D2 receptors and/or downregulation of D1 receptors. Unfortunately, the literature on cocaine-induced changes in dopaminergic receptor levels in rats is much more inconsistent than in NHP and human studies (Narendran and Martinez, 2008). Contributions to the variable results in rats could include many factors, including different infusion protocols and durations of drug abstinence following exposure, but fundamentally different responses to repeated cocaine infusion between species and animal strains cannot be excluded given the available data.

Alternatively, receptor neuroadaptations might be dissociated from metabolic consequences. Some evidence indicates that $\mathrm{D} 2$ receptors are targeted for degradation by the GASP-1 sorting protein following agonist-induced endocytosis, whereas D1 receptors are more rapidly recycled back to the cell surface (Bartlett et al, 2005); thus, D2 receptors may be more susceptible than D1 receptors to degradation owing to repeated dopaminergic stimulation. Initial studies on D2 regulation in cocaine-exposed GASP-1 knockout mice have produced conflicting results (Thompson et al, 2010; Boeuf et al, 2009), and one knockout strain exhibited an altered basal D1/D2 receptor ratio (Thompson et al, 2010).

Our study was not designed to assess longitudinal effects of chronic cocaine exposure. In each monkey, periods of repeated scanning were relatively short (3 months), and changes in the cumulative cocaine dose were relatively small $(25-50 \mathrm{mg} / \mathrm{kg})$. No obvious time-dependent changes in the cocaine-induced fMRI response were observed within these time periods. In one monkey, however, we performed one series of scans using a continuous 15 -min period of cocaine availability (Figure 1c), and then we performed a second series of scans 6 months later using alternating 5-min periods of cocaine availability, as in Figure 1d. The 6-month interval between successive sets of experiments included 3 months of cocaine abstinence followed by 3 months of selfadministration reinstatement, with a cumulative cocaine dose of $17 \mathrm{mg} / \mathrm{kg}$. Figure 6 shows repeated measurements of the cocaine-induced response in anterior basal ganglia during these two scanning periods. The response during the second scanning period was significantly smaller $(p<0.005$ across sessions) than during the first scanning period in all basal ganglia regions of interest, even though average doses $(0.51 \pm 0.10$ vs $0.45 \pm 0.18 \mathrm{mg} / \mathrm{kg})$ were not different. Differences between scanning periods were most pronounced in anterior putamen and nucleus accumbens. Although further experiments in more monkeys will be required to confirm a diminished fMRI response owing to chronic cocaine exposure, this effect is consistent with downregulation of D2 receptors and/or upregulation of D1 receptors, and suggests one possible reason as to why a robust negative fMRI

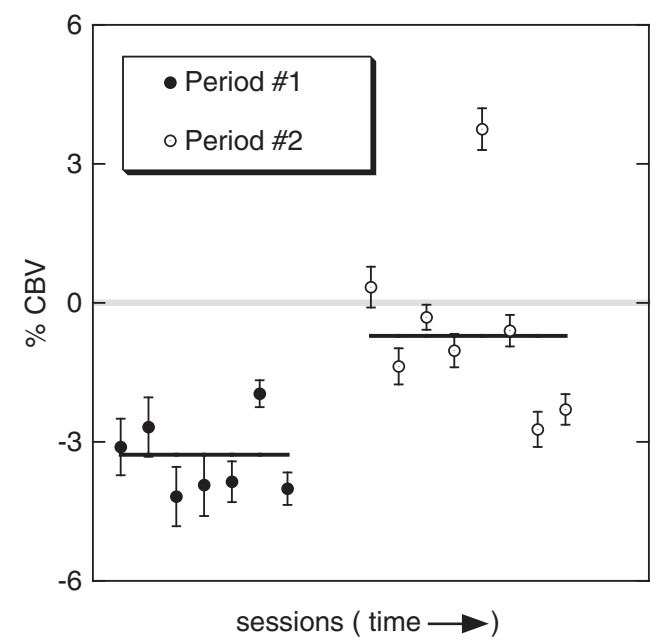

Figure 6 During two scanning periods separated by 3 months of cocaine abstinence and 3 months of reinstatement in one monkey, the negative response magnitude in one monkey $(\mathrm{MI})$ became statistically smaller, as assessed by repeated measurements across magnet sessions.

response in basal ganglia has not been reported in human subjects.

Given the opposite influences of $\mathrm{D} 1$ and $\mathrm{D} 2$ receptor stimulation on fMRI signal, cocaine-induced changes in receptor levels could not only diminish the fMRI response, but also make the cocaine-induced response invisible to fMRI. This possibility emphasizes the necessity to employ selective ligands using the fMRI modality to dissect cocaine pharmacology and neuroplasticity resulting from chronic exposure to cocaine or other drugs of abuse.

\section{Contingent Drug Administration Paradigms for fMRI in the NHP}

A somewhat surprising methodological result from these studies was the degree to which fMRI responses using complicated contingent infusion paradigms were accurately predicted from the shape of the non-contingent response to drug (Figure $1 \mathrm{c}$ and $\mathrm{d}$ ). This method of modeling the temporal response from a series of repeated injections assumes that each injection produces the same cerebral effect, so that responses sum linearly. Acute tolerance, a phenomenon in which repeated doses of cocaine produce progressively smaller effects, would be expected to reduce the accuracy of linear modeling. In human subjects, selfreports of cocaine craving are reduced during repeated cocaine infusions (Ward et al, 1997). In NHP, a bolus of $0.5 \mathrm{mg} / \mathrm{kg}$ cocaine elevates striatal extracellular dopamine by about $10-20 \%$ more than a subsequent bolus more than $1 \mathrm{~h}$ later (Bradberry, 2000).

In these experiments, data exhibited a consistent but nonsignificant trend for acute tolerance within runs, with the response during each period of drug availability reduced by about $10 \%$ relative to the previous period. When using a single regressor to describe the response to all three periods within each run, subtle effects from acute tolerance apparently were subsumed into regressors for baseline drift, such that it fits accurately the described data. However, the linear model may not work as well when using higher unit 
doses together with short inter-infusion intervals. For small unit doses as used in this study, however, the ability to accurately model repeated infusions facilitates experimental designs that simulate binge patterns of drug use or that produce desirable kinetics for the purpose of temporally separating drug stimulation from sensorimotor and cognitive processing.

\section{ACKNOWLEDGEMENTS}

We gratefully acknowledge financial support from the National Center for Biomedical Imaging and Bioengineering (R01EB001782, R03EB008134), the National Center for Drug Abuse (R01DA016187, R21DA021773), the National Institute of Neurological Disorders and Stroke (R21NS064432), and the National Science Foundation (0745436) in the USA, as well as the Fondation Bettencourt Schueller and the Inserm Avenir program in France. Helen Deng, MD, provided invaluable assistance in training animals, maintaining venous catheters, and coordinating procedures with the veterinary staff.

\section{DISCLOSURE}

The National Institutes of Health funded this work. The authors have no financial or competing interests to report pertaining to the research. BGJ has received financial support from BiogenIdec (Cambridge, MA) for work unrelated to the subject of this paper.

\section{REFERENCES}

Bartlett SE, Enquist J, Hopf FW, Lee JH, Gladher F, Kharazia V et al (2005). Dopamine responsiveness is regulated by targeted sorting of D2 receptors. Proc Natl Acad Sci USA 102: 11521-11526.

Beveridge TJ, Smith HR, Nader MA, Porrino LJ (2009). Abstinence from chronic cocaine self-administration alters striatal dopamine systems in rhesus monkeys. Neuropsychopharmacology 34: 1162-1171.

Black KJ, Gado MH, Perlmutter JS (1997). PET measurement of dopamine D2 receptor-mediated changes in striatopallidal function. J Neurosci 17: 3168-3177.

Boeuf J, Trigo JM, Moreau PH, Lecourtier L, Vogel E, Cassel JC et al (2009). Attenuated behavioural responses to acute and chronic cocaine in GASP-1-deficient mice. Eur J Neurosci 30: 860-868.

Booze R, Lehner A, Wallace D, Welch M, Mactutus C (1997). Dose-response cocaine pharmacokinetics and metabolite profile following intravenous administration and arterial sampling in unanesthetized, freely moving male rats. Neurotoxicol Teratol 19: 7-15.

Bradberry CW (2000). Acute and chronic dopamine dynamics in a nonhuman primate model of recreational cocaine use. J Neurosci 20: 7109-7115.

Bradberry CW (2007). Cocaine sensitization and dopamine mediation of cue effects in rodents, monkeys, and humans: areas of agreement, disagreement, and implications for addiction. Psychopharmacology (Berl) 191: 705-717.

Bradberry CW, Rubino SR (2006). Dopaminergic responses to self-administered cocaine in Rhesus monkeys do not sensitize following high cumulative intake. Eur J Neurosci 23: 2773-2778.

Breiter H, Gollub RL, Weisskoff RM, Kennedy D, Makris N, Berke J et al (1997). Acute effects of cocaine on human brain activity and emotion. Neuron 19: 591-611.
Charnay Y, Leger L, Vallet PG, Hof PR, Jouvet M, Bouras C (1995). $\left[{ }^{3} \mathrm{H}\right]$ Nisoxetine binding sites in the cat brain: an autoradiographic study. Neuroscience 69: 259-270.

Chen YC, Choi JK, Andersen SL, Rosen BR, Jenkins BG (2005). Mapping dopamine D2/D3 receptor function using pharmacological magnetic resonance imaging. Psychopharmacology (Berl) 180: 705-715.

Chen YI, Brownell AL, Galpern W, Isacson O, Bogdanov M, Beal MF et al (1999). Detection of dopaminergic cell loss and neural transplantation using pharmacological MRI, PET and behavioral assessment. Neuroreport 10: 2881-2886.

Chen YI, Choi JK, Xu H, Ren J, Andersen SL, Jenkins BG (2010). Pharmacologic neuroimaging of the ontogeny of dopamine receptor function. Dev Neurosci 32: 125-138.

Chen YI, Mandeville JB, Nguyen TV, Talele A, Cavagna F, Jenkins BG (2001). Improved mapping of pharmacologically induced neuronal activation using the IRON technique with superparamagnetic iron blood pool agents. J Magn Reson Imaging 14: 517-524.

Choi JK, Chen YI, Hamel E, Jenkins BG (2006). Brain hemodynamic changes mediated by dopamine receptors: role of the cerebral microvasculature in dopamine-mediated neurovascular coupling. NeuroImage 30: 700-712.

Choi JK, Deng H, Vanduffel W, Mandeville JB (2009). fMRI of cocaine self-administration in non-human primates. Paper Presented at the International Society of Magnetic Resonance Medicine, Honolulu, HI

Dumartin B, Caille I, Gonon F, Bloch B (1998). Internalization of D1 dopamine receptor in striatal neurons in vivo as evidence of activation by dopamine agonists. J Neurosci 18: 1650-1661.

Evans SM, Cone EJ, Henningfield JE (1996). Arterial and venous cocaine plasma concentrations in humans: relationship to route of administration, cardiovascular effects and subjective effects. J Pharmacol Exp Ther 279: 1345-1356.

Febo M, Segarra AC, Nair G, Schmidt K, Duong TQ, Ferris CF (2005). The neural consequences of repeated cocaine exposure revealed by functional MRI in awake rats. Neuropsychopharmacology 30: 936-943.

Ferry AT, Ongur D, An X, Price JL (2000). Prefrontal cortical projections to the striatum in macaque monkeys: evidence for an organization related to prefrontal networks. J Comp Neurol 425: 447-470.

Flory GS, Woods JH (2003). The ascending limb of the cocaine dose-response curve for reinforcing effect in rhesus monkeys. Psychopharmacology (Berl) 166: 91-94.

Fowler JS, Volkow ND, Wolf AP, Dewey SL, Schlyer DJ, MacGregor RR et al (1989). Mapping cocaine binding sites in human and baboon brain in vivo. Synapse 4: 371-377.

Gatley SJ, Volkow ND, Wang GJ, Fowler JS, Logan J, Ding YS et al (2005). PET imaging in clinical drug abuse research. Curr Pharm Des 11: 3203-3219.

Gnegy ME, Khoshbouei H, Berg KA, Javitch JA, Clarke WP, Zhang $\mathrm{M}$ et al (2004). Intracellular $\mathrm{Ca}^{2+}$ regulates amphetamineinduced dopamine efflux and currents mediated by the human dopamine transporter. Mol Pharmacol 66: 137-143.

Goldman-Rakic PS, Bergson C, Krimer LS, Lidow MS, Williams SM, Wiliams GV (1999). Chapter V: the primate mesocortical dopamine system. In: Bloom FE, Bjorklund A, Hokfelt T (eds). Handbook of Chemical Neuroanatomy. Amsterdam: Elsevier. pp 403-428.

Griswold MA, Jakob PM, Heidemann RM, Nittka M, Jellus V, Wang J et al (2002). Generalized autocalibrating partially parallel acquisitions (GRAPPA). Magn Reson Med 47: 1202-1210.

Haber SN, Calzavara R (2009). The cortico-basal ganglia integrative network: the role of the thalamus. Brain Res Bull 78: 69-74.

Hall H, Sedvall G, Magnusson O, Kopp J, Halldin C, Farde L (1994). Distribution of D1- and D2-dopamine receptors, and dopamine 
and its metabolites in the human brain. Neuropsychopharmacology 11: 245-256.

Howell LL, Hoffman JM, Votaw JR, Landrum AM, Wilcox KM, Lindsey KP (2002). Cocaine-induced brain activation determined by positron emission tomography neuroimaging in conscious rhesus monkeys. Psychopharmacology (Berl) 159: 154-160.

Howell LL, Votaw JR, Goodman MM, Lindsey KP (2010). Cortical activation during cocaine use and extinction in rhesus monkeys. Psychopharmacology (Berl) 208: 191-199.

Huang Y, Hwang DR, Narendran R, Sudo Y, Chatterjee R, Bae SA et al (2002). Comparative evaluation in nonhuman primates of five PET radiotracers for imaging the serotonin transporters: $\left[{ }^{11} \mathrm{C}\right] \mathrm{McN}$ 5652, $\left[{ }^{11} \mathrm{C}\right] \mathrm{ADAM},\left[{ }^{11} \mathrm{C}\right] \mathrm{DASB},\left[{ }^{11} \mathrm{C}\right] \mathrm{DAPA}$, and $\left[{ }^{11}\right.$ C]AFM. J Cereb Blood Flow Metab 22: 1377-1398.

Hyttel J, Arnt J (1987). Characterization of binding of ${ }^{3} \mathrm{H}-\mathrm{SCH}$ 23390 to dopamine D-1 receptors. Correlation to other D-1 and D-2 measures and effect of selective lesions. J Neural Transm 68: 171-189.

Jakovcevic D, Harder DR (2007). Role of astrocytes in matching blood flow to neuronal activity. Curr Top Dev Biol 79: 75-97.

Jarraya B, Arsenault J, Van Kerkoerle T, Ekstrom L, Mandeville JB, Marota JJA et al (2007). Predictive reward value related fMRI activations in macaque. Paper Presented at the Society for Neuroscience, San Diego, CA

Jenkins BG, Sanchez-Pernaute R, Brownell AL, Chen YC, Isacson O (2004). Mapping dopamine function in primates using pharmacologic magnetic resonance imaging. J Neurosci 24: 9553-9560.

Kalivas PW, Stewart J (1991). Dopamine transmission in the initiation and expression of drug- and stress-induced sensitization of motor activity. Brain Res Brain Res Rev 16: 223-244.

Kirkland Henry P, Davis M, Howell LL (2009). Effects of cocaine self-administration history under limited and extended access conditions on in vivo striatal dopamine neurochemistry and acoustic startle in rhesus monkeys. Psychopharmacology (Berl) 205: 237-247.

Kufahl P, Li Z, Risinger R, Rainey C, Piacentine L, Wu G et al (2008). Expectation modulates human brain responses to acute cocaine: a functional magnetic resonance imaging study. Biol Psychiatry 63: 222-230.

Kufahl PR, Li Z, Risinger RC, Rainey CJ, Wu G, Bloom AS et al (2005). Neural responses to acute cocaine administration in the human brain detected by fMRI. NeuroImage 28: 904-914.

Leite FP, Tsao D, Vanduffel W, Fize D, Sasaki Y, Wald LL et al (2002). Repeated fMRI using iron oxide contrast agent in awake, behaving macaques at 3 Tesla. NeuroImage 16: 283-294.

Lewis JW, Van Essen DC (2000). Mapping of architectonic subdivisions in the macaque monkey, with emphasis on parieto-occipital cortex. J Comp Neurol 428: 79-111.

London ED, Cascella NG, Wong DF, Phillips RL, Dannals RF, Links JM et al (1990). Cocaine-induced reduction of glucose utilization in human brain. Arch Gen Psychiatry 47: 567-574.

Lu H, Xi ZX, Gitajn L, Rea W, Yang Y, Stein EA (2007). Cocaineinduced brain activation detected by dynamic manganeseenhanced magnetic resonance imaging (MEMRI). Proc Natl Acad Sci USA 104: 2489-2494.

Lyons D, Friedman DP, Nader MA, Porrino LJ (1996). Cocaine alters cerebral metabolism within the ventral striatum and limbic cortex of monkeys. J Neurosci 16: 1230-1238.

Madras BK, Fahey MA, Canfield DR, Spealman RD (1988). D1 and D2 dopamine receptors in caudate-putamen of nonhuman primates (Macaca fascicularis). J Neurochem 51: 934-943.

Mandeville JB, Ekstrom L, Marota JJA, Jenkins BG, Vanduffel W (2005). Contrast-enhanced fMRI of cocaine action in awake non-human primate. Paper Presented at the International Society of Magnetic Resonance Medicine, Miami, FL.

Mandeville JB, Jenkins BG, Chen YC, Choi JK, Kim YR, Belen D et al (2004). Exogenous contrast agent improves sensitivity of gradient-echo functional magnetic resonance imaging at $9.4 \mathrm{~T}$. Magn Reson Med 52: 1272-1281.

Mandeville JB, Jenkins BG, Kosofsky BE, Moskowitz MA, Rosen BR, Marota JJA (2001). Regional sensitivity and coupling of BOLD and CBV changes during stimulation of rat brain. Magn Reson Med 45: 443-447.

Mandeville JB, Marota JJA, Kosofsky BE, Keltner JR, Weissleder R, Rosen BR et al (1998). Dynamic functional imaging of relative cerebral blood volume during rat forepaw stimulation. Magn Reson Med 39: 615-624.

Marota JJA, Mandeville JB, Weisskoff RM, Moskowitz MA, Rosen BR, Kosofsky BE (2000). Cocaine activation discriminates dopamergic projections by temporal response: an fMRI study in rat. NeuroImage 11: 13-23.

Martinez D, Narendran R, Foltin RW, Slifstein M, Hwang DR, Broft A et al (2007). Amphetamine-induced dopamine release: markedly blunted in cocaine dependence and predictive of the choice to self-administer cocaine. Am J Psychiatry 164: 622-629.

McCann UD, Wong DF, Yokoi F, Villemagne V, Dannals RF, Ricaurte GA (1998). Reduced striatal dopamine transporter density in abstinent methamphetamine and methcathinone users: evidence from positron emission tomography studies with [ $\left.{ }^{11} \mathrm{C}\right]$ WIN-35,428. J Neurosci 18: 8417-8422.

McLaren DG, Kosmatka KJ, Oakes TR, Kroenke CD, Kohama SG, Matochik JA et al (2009). A population-average MRI-based atlas collection of the rhesus macaque. NeuroImage 45: 52-59.

Moore RJ, Vinsant SL, Nader MA, Porrino LJ, Friedman DP (1998a). Effect of cocaine self-administration on dopamine D2 receptors in rhesus monkeys. Synapse 30: 88-96.

Moore RJ, Vinsant SL, Nader MA, Porrino LJ, Friedman DP (1998b). Effect of cocaine self-administration on striatal dopamine D1 receptors in rhesus monkeys. Synapse 28: 1-9.

Nader MA, Daunais JB, Moore T, Nader SH, Moore RJ, Smith HR et al (2002). Effects of cocaine self-administration on striatal dopamine systems in rhesus monkeys: initial and chronic exposure. Neuropsychopharmacology 27: 35-46.

Nader MA, Morgan D, Gage HD, Nader SH, Calhoun TL, Buchheimer $\mathrm{N}$ et al (2006). PET imaging of dopamine D2 receptors during chronic cocaine self-administration in monkeys. Nat Neurosci 9: 1050-1056.

Narendran R, Martinez D (2008). Cocaine abuse and sensitization of striatal dopamine transmission: a critical review of the preclinical and clinical imaging literature. Synapse 62: 851-869.

Nguyen TV, Brownell AL, Iris Chen YC, Livni E, Coyle JT, Rosen BR et al (2000). Detection of the effects of dopamine receptor supersensitivity using pharmacological MRI and correlations with PET. Synapse 36: 57-65.

Nikulina EM, Kapralova NS (1992). Role of dopamine receptors in the regulation of aggression in mice; relationship to genotype. Neurosci Behav Physiol 22: 364-369.

Pfeuffer J, Shmuel A, Keliris GA, Steudel T, Merkle H, Logothetis NK (2007). Functional MR imaging in the awake monkey: effects of motion on dynamic off-resonance and processing strategies. Magn Reson Imaging 25: 869-882.

Piggott MA, Marshall EF, Thomas N, Lloyd S, Court JA, Jaros E et al (1999). Dopaminergic activities in the human striatum: rostrocaudal gradients of uptake sites and of D1 and D2 but not of D3 receptor binding or dopamine. Neuroscience 90: 433-445.

Porrino LJ (1993). Functional consequences of acute cocaine treatment depend on route of administration. Psychopharmacology 112: 343-351.

Puglisi-Allegra S, Cabib S (1988). Pharmacological evidence for a role of D2 dopamine receptors in the defensive behavior of the mouse. Behav Neural Biol 50: 98-111.

Richfield EK, Young AB, Penney JB (1989). Comparative distributions of dopamine $\mathrm{D}-1$ and $\mathrm{D}-2$ receptors in the cerebral cortex of rats, cats, and monkeys. J Comp Neurol 286: 409-426. 
Risinger RC, Salmeron BJ, Ross TJ, Amen SL, Sanfilipo M, Hoffmann RG et al (2005). Neural correlates of high and craving during cocaine self-administration using BOLD fMRI. NeuroImage 26: 1097-1108.

Ritz MC, Cone EJ, Kuhar MJ (1990). Cocaine inhibition of ligand binding at dopamine, norepinephrine and serotonin transporters: a structure-activity study. Life Sci 46: 635-645.

Rogers KJ, Nahorski SR (1973). Depression of cerebral metabolism by stimulant doses of cocaine. Brain Res 57: 255-258.

Saleem KS, Logothetis NK (2006). A Combined MRI and Histology Atlas of the Rhesus Monkey Brain. Academic Press: London, UK.

Sanchez-Pernaute R, Jenkins BG, Choi JK, Iris Chen YC, Isacson O (2007). In vivo evidence of D3 dopamine receptor sensitization in parkinsonian primates and rodents with L-DOPA-induced dyskinesias. Neurobiol Dis 27: 220-227.

Schmidt KF, Febo M, Shen Q, Luo F, Sicard KM, Ferris CF et al (2006). Hemodynamic and metabolic changes induced by cocaine in anesthetized rat observed with multimodal functional MRI. Psychopharmacology (Berl) 185: 479-486.

Schwarz AJ, Zocchi A, Reese T, Gozzi A, Garzotti M, Varnier G et al (2004). Concurrent pharmacological MRI and in situ microdialysis of cocaine reveal a complex relationship between the central hemodynamic response and local dopamine concentration. NeuroImage 23: 296-304.

Seneca N, Gulyas B, Varrone A, Schou M, Airaksinen A, Tauscher J et al (2006). Atomoxetine occupies the norepinephrine transporter in a dose-dependent fashion: a PET study in nonhuman primate brain using $(S, S)-\left[{ }^{18} \mathrm{~F}\right] \mathrm{FMeNER}-\mathrm{D} 2$. Psychopharmacology (Berl) 188: 119-127.

Sharkey J, McBean DE, Kelly PAT (1991). Acute cocaine administration: effects on local cerebral blood flow and metabolic demand in the rat. Brain Res 548: 310-314.

Stein EA, Fuller SA (1993). Cocaine's time action profile on regional cerebral blood flow in the rat. Brain Res 626: 117-126.

Sweidan S, Edinger H, Siegel A (1990). The role of D1 and D2 receptors in dopamine agonist-induced modulation of affective defense behavior in the cat. Pharmacol Biochem Behav 36: 491-499.

Thanos PK, Michaelides M, Benveniste H, Wang GJ, Volkow ND (2008). The effects of cocaine on regional brain glucose metabolism is attenuated in dopamine transporter knockout mice. Synapse 62: 319-324.

Thompson D, Martini L, Whistler JL (2010). Altered ratio of D1 and D2 dopamine receptors in mouse striatum is associated with behavioral sensitization to cocaine. PLoS One 5: e11038.
Tsukada H, Nishiyama S, Kakiuchi T, Ohba H, Sato K, Harada N (2001). Ketamine alters the availability of striatal dopamine transporter as measured by [(11)C]beta-CFT and [(11)C]betaCIT-FE in the monkey brain. Synapse 42: 273-280.

Van Essen DC, Drury HA, Dickson J, Harwell J, Hanlon D, Anderson CH (2001). An integrated software suite for surface-based analyses of cerebral cortex. J Am Med Inform Assoc 8: 443-459.

Vanduffel W, Fize D, Mandeville JB, Nelissen K, Van Hecke P, Rosen BR et al (2001). Visual motion processing investigated using contrast-enhanced fMRI in awake behaving monkeys. Neuron 32: 565-577.

Vanduffel W, Fize D, Peuskens H, Denys K, Sunaert S, Todd JT et al (2002). Extracting 3D from motion: differences in human and monkey intraparietal cortex. Science 298: 413-415.

Volkow ND, Fowler JS, Wang G-J, Hitzemann R, Logan J, Schlyer DJ et al (1993). Decreased dopamine D2 receptor availability is associated with reduced frontal metabolism in cocaine abusers. Synapse 14: 169-177.

Volkow ND, Fowler JS, Wolf AP, Schlyer D, Shiue C-Y, Alpert R et al (1990). Effects of chronic cocaine abuse on postsynaptic dopamine receptors. Am J Psychiatry 147: 719-724.

Volkow ND, Wang G-J, Fowler JS, Logan J, Gatley SJ, Hitzemann R et al (1997). Decreased striatal dopaminergic responsiveness in detoxified cocaine-dependent subjects. Nature 386: 830-833.

Ward AS, Haney M, Fischman MW, Foltin RW (1997). Binge cocaine self-administration in humans: intravenous cocaine. Psychopharmacology (Berl) 132: 375-381.

Weed MR, Woolverton WL, Paul IA (1998). Dopamine D1 and D2 receptor selectivities of phenyl-benzazepines in rhesus monkey striata. Eur J Pharmacol 361: 129-142.

Weerts EM, Fantegrossi WE, Goodwin AK (2007). The value of nonhuman primates in drug abuse research. Exp Clin Psychopharmacol 15: 309-327.

Worsley KJ, Liao CH, Aston J, Petre V, Duncan GH, Morales F et al (2002). A general statistical analysis for fMRI data. NeuroImage 15: 1-15.

Worsley KJ, Marrett S, Neelin P, Vandal AC, Friston KJ, Evans AC (1996). A unified statistical approach for determining significant signals in images of cerebral activation. Hum Brain Mapp 4: $58-73$.

Zocchi A, Conti G, Orzi F (2001). Differential effects of cocaine on local cerebral glucose utilization in the mouse and in the rat. Neurosci Lett 306: 177-180. 